\title{
Reflexões sobre prácticas de sala-de- aula e competências na formaçãos de profesores da universidade de Colônia, Alemanha.
}

\section{Reviwing classroom practice and competence of teacher education at the university of Cologne, Germany.}

\section{Helza Ricarte Lanz}

Koln University

helzalanz@icloud.com

Ricarte Lanz, H. (2017). O semestre prático na formação de professores do ensino fundamental e médio da Universidade de Colônia, Alemanha. Revista Prácticum, Vol 1(1) 99-113. ISSN 2530-4550

Fecha de recepción: 25 de noviembre 2016

Fecha de revisión: 20 diciembre de 2016

Fecha de aceptación: 4 de enero de 2017 


\section{Resumo:}

O objetivo desse artigo é refletir sobre as práticas introduzidas pelo Processo de Bolonha e seu foco em competências, performatividade e boas-práticas. Primeiramente, será analisada a definică de educação dentro da tradição pedagógica alemã. 0 segundo tópico apresenta o semestre prático na formac馬 de professores do ensino fundamental e médio da Universidade de Colônia, Alemanha. O terceiro tópico discute as práticas de sala-deaula e questiona os problemas educacionais inerentes ao atual sistema europeu. Concluímos que a educação ora em curso pode significar graves riscos à sua qualidade.

\section{Abstract:}

The aim of the article is to reflect practice standards introduced by the Bologna Process, focussing on the development of competence, performance and good-practice. Initially, the definition of education in the German pedagogical tradition will be analysed. Next, the University of Cologne's (Germany) concept of teacher education, including the practical semester as an innovative approach, is reviewed. Finally, a comparison between this new approach and the traditional concept of education will be performed, where we conclude that adapting education to economical and political needs can lead to serious risks of its quality.

\section{Palavras-chave:}

Educação, formação de professores, semestre prá-tico, competência, performatividade

\section{Key words:}

Education, teacher education, practical semester, competence, performance 


\section{Introdução}

A vida contemporânea da denominada "sociedade da informação e do conhecimento em expansão" exige a habilidade de saber lidar com novos desafios e requer uma escola que prepara seus alunos para esses desafios (Keck 1997; Hörster 2010; Roters 2012). Dada a rapidez das mudancas, naõ basta a qualificac馬, já que esta pode tornar-se obsoleta em curto prazo. E'necessaŕia a capacidade de continuamente adaptar-se frente as̀ mudancass tecnológicas e as̀ novas demandas do trabalho e da vida social.

A princípio, essas afirmações parecem ser ponto pacífico e lugar comum nos ávidos apelos das agências internacionais por reformas de ensino na contemporaneidade. Se por um lado, essas constatações nos remetem a indagações sobre a educação: como deve ser concebida a formação docente para o exercício do magistério em escolas que fomentam individualmente seus alunos e que, concomitantemente, promovem sua inclusão social, preparandoos para o futuro? Que tipo de práticas, métodos e avaliações são necessários para a formacaळ de professores? Por outro lado, dada a complexidade da vida contemporânea e dos objetivos da educação e formação de professores, essas perguntas exigem um olhar mais atento para as propostas subjacentes às mesmas.

Num passado não muito distante, a multiplicidade de instituic馬s de ensino superior e, logo, de saberes, conhecimentos, práticas e modos organizacionais acadêmicos existentes na Europa sempre foi algo positivo antes de ser um problema! A diversidade de idéias, conhecimentos, saberes e práticas proporcionaram os mais variados intercambios e parcerias, tanto em pesquisa quanto em ensino. Paradoxalmente a esta elevac馬 da diversidade e riqueza acadêmica surge, nas últimas décadas do século $X X$ e mais especificamente no ano de 1998, uma proposta de unificac司历 e de reforma dos diversos sistemas de educacă superior na Europa eivada de matizes políticoeconômicas e tecnológicas. Naquele ano, os ministros da educacă da Alemanha, Franc回 Italía e Reino Unido firmaram a Declaracaõ de Sorbonne, prelúdio do que viria a ser assumido no ano seguinte. Em 1999, vinte e nove paiśes assinam a Declaracă de Bolonha, concordando em coloca-la em pleno funcionamento ate'o ano de 2010, o que de fato concretizou-se na Alemanha e alhures. 
O Processo de Bolonha gerou uma série de reformas ducacionais ${ }^{1}$. Podemos listar algumas das dimensoẽs contidas na Declaração de Bolonha (1999), tais como: a organizaca历 do ciclo de estudo de modo padronizado no Espacb Europeu de EducacБ历 Superior (licenciatura/ bacharelado, mestrado e doutorado); a homogeneizacaळ do sistema de creditos; a mobilidade internacional; a cooperaca̋ nas pratícas de

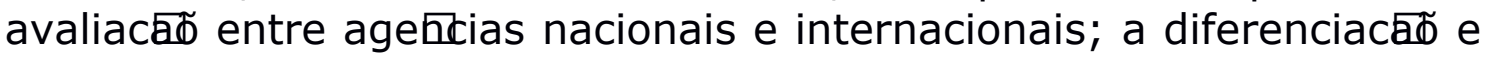
competicä interinstitucional destinada a responder a demandas de mercado; a perda de protagonismo dos estados nacionais na regulac馬 da educacБळ superior; a preponderaßicia de uma agenda transnacional; o baixo grau de participac馬 dos atores institucionais universitaŕios no processo de tomada de decisoẽs - algo que não condiz com práticas democráticas - e o uso cada vez mais intenso de tecnologias da informac馬 no processo de ensino-aprendizagem.

Além do sistema sequencial entre licenciatura (bacharelado) e mestrado, a maioria das instituições adequou-se também ao sistema europeu de transferência de créditos (European Credit Transfer Systems - ECTS) e ao processo de comparação de qualidade do ensino por meio de testes avaliativos (p.ex. PISA), que tem como objetivos promover a empregabilidade e a competitividade do sistema europeu de ensino superior. Tratou-se de uma abertura das universidades no sentido de atender às demandas requeridas pelo mercado global. Em suma, podemos verificar que o Processo de Bolonha define, entre outras, as seguintes linhas de acă: 1) Adocă de um sistema de graus acadêmicos facilmente legivel, quantificável e comparav́el; 2) Adocā̋ de um sistema padronizado, essencialmente baseado em ciclos com ênfase no desenvolvimento de competências.

É dentro desse panorama internacional que busca-se discutir as práticas de salas-de aula na formacaळ de professores. O objetivo desse artigo é refletir sobre o Processo Bolonha e sua ênfase no desenvolvimento de competências e boas-práticas. Para esse objetivo, primeiramente definirei o significado do que venha a ser educação, a Bildung, na tradição pedagógica alemã. Num segundo tópico, apresentarei o semestre prático e o E-Porfólio - elo formal entre as diversas instâncias, instituições e fases da formação profissional - como elementos inovadores dentro da formação de professores da Universidade de Colônia, Alemanha. O terceiro tópico discute algumas premissas da prática de sala-de-aula por competências e performatividade, questionando os problemas educacionais inerentes à proposta do atual sistema europeu. Concluímos que,

1 A história do Processo de Bolonha pode ser lida resumidamente na fonte: http://www.unl.pt/ en/university/Um_pouco_de_historia/pid=240/ppid=79/ Acesso em: 13.01.2017 
nesse sistema europeu de unificação do ensino superior, um dos mais graves riscos e equívocos da educacă reside em admitir a perspectiva educacional adaptativa aos ditames político-econômicos e aos avanços tecnológicos.

\section{Bildung -o conceito de edcação na alemanha}

Em alemão, existem duas palavras para o conceito de educação: Bildung e Erziehung. Enquanto a palavra Bildung tem um sentido amplo e universalista, a palavra Erziehung tem um sentido mais restrito da relação educador-educando dentro do processo de socialização dos individuos numa sociedade. Obviamente, os dois conceitos são importantes e estabelecem uma relação próxima entre si, porém não significam a mesma coisa.

Erziehung significa uma ação intencional de intervenção (pedagógica) para influenciar o desenvolvimento de uma criança ou um adolescente, ou um sujeito. Já o conceito de Bildung é o processo de constituică, formacă e transformação do sujeito no decurso próprio e ativo do seu devir a ser no mundo. A pretensaõ de universalidade, proṕria do oitocentismo alemaõ [Iluminismo(Aufklaurung), Romantismo, Idealismo], faz com que a Bildung seja a busca, proṕria do ser humano, da constituică de uma formacaळ que deßsentido ao seu ser-no-mundo. Feita essa ressalva, abordaremos o conceito de Bildung nas linhas subsequentes, já que, apesar de ser um conceito muito discutido, controverso em alguns pontos, o termo Bildung é um conceito central do pensar pedagógico alemão.

Impoẽ-se, nessa breve análise, a idéia iluminista de que a educacă possibilita a emancipação, capacita e habilita o sujeito a conseguir determinar sua vida de forma consciente, autoநbma, superando as condicб̈̈s de alienacă social, nas quais esta'inserido. O conceito tem uma longa história que remonta à idade média ( $v$. entre outros Koller 2012; 2016), não vamos nos deter a ela. Vale ressaltar que a proposta iluminista de Bildung surge, assim, como algo inseparav́el de uma profunda vontade de divulgacaळ do saber e da educac师 das massas (v. Humboldt 1960). A compreensaõ de Bildung pressupoẽ uma acБळ formativa bastante abrangente, pois cabe manter conexoẽs intrińsecas não apenas com os saberes, com os conhecimentos, com as técnicas, como assim também com as artes, com a etica, com as culturas e seus idiomas para efetivar uma formacaळ integral do individuo. Dai' a consideracă de a sua complexidade ser um fator taõ determinante para sua apreensaõ. 
O conceito de Bildung, obviamente, mudou com o tempo, mas, em essencia, sempre refere-se a evoluca्b do potencial do individuo, o que Ihe confere uma importanicia fundamental enquanto conceito de base para as ciehicias da educacăo. Assim sendo, Bildung está revestido de um significado duplo, a saber: o ideal pedagógico formativo institucional, social, cultural, e o ideal de uma autoformação, onde o sujeito não está vinculado necessariamente a uma instituică de ensino. Portanto, deve-se compreender esse conceito como um processo emancipatório do devir humano.

O conceito pedagógico-filosófico de Bildung está relacionado aos verbos criar-se, desenvolver-se, constituir-se, instruir-se. O sentido reflexivo imposto pelo conceito Bildung é indicador de uma ação consciente, cujo o agente só pode ser o próprio sujeito na sua relação consigo e com o mundo num processo pedagógico autoformador e autotransformador. Percebe-se, assim, a forcaldialetíca da Bildung: Educação naõ e apenas o resultado final de um processo pedagoǵico (apreensaõ do conhecimento acumulado culturalmente), mas o proṕrio processo emancipatório de formacă do homem integral.

\section{A formação docente na universidades de colônia}

O curso de educação para o magistério é o sexto colocado em número de estudantes na Alemanha (Faulstich e Faulstich-Wieland 2008, p. 9) e a formação de professores está direcionada ao tipo de escola que o estudante irá lecionar. Ao ingressar no curso de educação para o magistério, o estudante escolhe o tipo de escola e duas áreas do conhecimento (disciplinas) que norteiam a formação básica e as escolhas das disciplinas obrigatórias e optativas. Durante o bacharelado, é necessário fazer o estágio de aptidão para o magistério, obter orientação sobre a prática professional para estar seguro que a escolha acadêmica adequa-se às aptidões pessoais.

Após o bacharelado, ao concluir o Master of Education, há o estágio remunerado de um ano e meio numa escola pública para habilitar-se para o magistério. Os 4 semestres do mestrado incluem, entre outros, o módulo obrigatório de inovação pedagógica com a prática de pesquisa empírica, o módulo de alemão como segunda língua, dado à quantidade expressiva de crianças estrangeiras nas escolas, bem como o semestre prático, enquanto qualificações necessárias para a elaboração da tese de mestrado.

\subsection{O semestre práctico na formação de profesores do ensino fundamental e médio da universidade de Colônia}

O semestre prático dentro do Master of Education é o resultado de um trabalho conjunto e supra-institucional da força-tarefa de mais 
de 500 atores sociais da Universidade de Colônia, das Faculdades de Esporte, de Música e Dança (Deutsche Sporthochschule und Hochschule fuĐMusik und Tanz), das escolas públicas da região metropolitana de Colônia e dos centros de formação de professores (Zentrum fuE schulpraktische Lehrerausbildung - ZfsL), conforme definido pela Lei de Diretrizes (LABG 2009). As atividades de prática de aula e de pesquisa empírica são a base do semestre prático, cuja duração é de um ano letivo, isto é, 750 horas/aulas de teoria e prática em sala de aula, sendo 360 horas na universidade e 390 horas nas escolas e nos centros de formação docente (ZfSL). Portanto, três instituições são responsáveis pelo semestre prático: Universidade de Colônia, Centro de Formação de Professores (Zentrum fü Lehrerausbildung - ZfsL) e as escolas públicas do ensino fundamental e médio da região de Colônia, que inclui também as cidades de Engelskirchen, Leverkusen e Siegburg.

Durante as dez primeiras semanas do semestre prático, os estudantes recebem aulas teóricas de métodos de pesquisa empírica, didática, alemão enquanto segunda língua e interpretação no grupo padrão (até 60 alunos). Posteriormente, de acordo com a ênfase escolhida, o estudante será acompanhado pelo grupo de perfil (5-10 participantes) até a entrega e avaliação do prometo individual de pesquisa e sua prática de sala de aula, documentados no e-portfólio.

O modelo do semestre prático da Universidade de Colônia aposta no acompanhamento individualizado dos estudantes, no desenvolvimento teórico-prático de competências profissionais, na valorização e desenvolvimento da reflexão e da pesquisa. O desenvolvimento desse habitus (Bourdieu 1974) reflexivo de professor-pesquisador, que une teoria e prática, deve acompanhar a formação e vida profissional docente.

A lei de diretrizes de base (LABG $2009 \S 12,1$ ) e o decreto para habilitação de profesores (Lehramtzugangsverordnung - LZV 2009, §13) definem que os elementos práticos da formação para 0 magistério serão documentados no portfólio do estudante. $\mathrm{Na}$ Universidade de Colônia, o e-portfólio é o elo formal entre as fases da formação profissional. Nesse e-portfólio, ficam documentadas as fases da formação docente: estágio de aptidão para a docência; estágio do semestre prático e, ao final do mestrado, estágio remunerado de um ano e meio em uma escola pública.

\subsubsection{O caráter inovador do E-Portfólio do Semestre Prático}

O acompanhamento individual, flexível e independente de cada 
estudante dá-se através de aulas presencias, complementadas por elearning. Os alunos podem fazer uso de recursos eletrônicos, tais como: módulos de aprendizagem online, testes de autocontrole, podcasts, blogs, chats, foros e o portfólio eletrônico. Todos os recursos são ofertados pela plataforma ILIAS da Universidade de Colônia (www.ilias.uni-koeln.de). O portfólio eletrônico constitui a base da qualificação docente ao final do semestre prático.

O Centro de Formação Docente (ZfL) oferece um curso introdutório sobre como trabalhar com o e-portfólio antes do início do semestre prático. Nas primeiras dez semanas, os estudantes participam de um seminário preparatório para o semestre prático, refletem sobre seu autoconceito pessoal e profissional e seus objetivos profissionais. No seminário de acompanhamento, dentro do grupo de perfil com cinco a dez participantes, são elaborados os projetos de pesquisa e de aulas que pretendem executar individualmente. $\mathrm{Na}$ escola, os estudantes visitam, observam, elaboram e ministram aulas sob supervisão de professores universitários, professores do centro de formação docente ( $Z f L$ ) e professores das escolas. O cerne do e-portfólio são as reflexões individuais de 5 Standards, cujas linhas serão apresentadas a seguir:

- O Standard 1 diz respeito à competência ensino-aprendizagem na escola e está baseado nos fundamentos pedagógicos e didáticos que o estudante adquiriu ao longo da sua formação para planejar, executar e refletir sobre suas próprias aulas. Como parte da documentação comprobatória, o estudante deve anexar suas anotações de aula, as notas de supervisão, o "feedback" dos alunos, bem como dos materiais e recursos utilizados em sala de aula.

- O Standard 2 refere-se às estratégias pedagógicas de diagnóstico e de avaliação, à capacidade de fomentar individualmente os alunos e de refletir sobre as práticas pedagógicas. Anotações, protocolos, observações de aula, avaliações, materiais usados para promover o fomento individual das/os alunas/os são documentados, além dos materiais que embasam as reflexões do estudante, inclusive livros e anotações de seminários.

- O Standard 3 refere-se à educação, socialização, interação e comunicação, definidas como tarefas elementares de professoras e professores. Para tal, o estudante pode explorar, conhe-cer e questionar esses campos de atuação docente. Além das notas pessoais, o regulamento da escola, o programa de ensino, a carta escolar, os contratos da escola com instituições afins, conceitos e programas de cidadania e educação política, 
os conceitos de mediação pedagógica e propostas de envolvimento familiar nas atividades escolares podem ser documentados.

- O Standard 4 documenta o projeto de pesquisa empírica pedagógica, onde a/o estudante investiga um aspecto da escola, do sistema escolar ou da prática de sala de aula. Nesse sentido, esse projeto exploratório fundamentado teoricamente pode ajudar a unir teoria e prática e desenvolver uma postura pesquisadora no futuro docente.

- O Standard 5 refere-se ao autoconceito profissional, onde o estudante sistematiza métodos e boas práticas de ensinoaprendizagem e identifica quais conhecimentos e competências seus alunos devem adquirir.

Refletir sobre suas ações, saber pesquisar, ministrar aulas, dialogar, documentar, comunicar e compartilhar seus conhecimentos são as competências-chave que contribuem para um elevado grau de profis-sionalismo pedagógico (Combe e Kolbe 2008; Faulstich e Faulstich-Wieland 2008; Hörster 2010; Roters 2012). O e-portfólio e o se-mestre prático são os instrumentos didáticos mais inovadores na formação para o magistério da Universidade de Colônia, auxiliando, apoiando e reforçando o desenvolvimento dessas competências.

O que teoricamente apresenta-se como um avanço revela-se, na prática, como uma reforma contrária aos objetivos pedagógicos. As experiências atuais mostram que nem a mobilidade internacional prevista na Declaração de Bolonha foi alcançada, nem a evasão dos estudantes diminuiu. As grades curriculares dos cursos das faculdades de educação não ficaram nem mais claras, nem estão bem definidas, nem são comparáveis. Segundo Krautz (2013), as decisões de Bolonha e os processos de reforma desencadeados nas instituições européias de ensino superior não foram democráticas e, até hoje, não há diálogo nem com os países, nem com as instituições de ensino superior.

Uma justificativa científico-pedagógica para as reformas do Processo de Bolonha permanece inexistente. O ensino superior foi fragmentado em duas fases e regulamentado por dispositivos, regras, testes, documentações, avaliações e controles que sobrecarregam objetiva-mente uma abordagem pedagógica mais dinâmica e flexível. Segundo as agências interessadas nas reformas de ensino superior, é a partir das acБ̈s da pratíca profissional, preferencialmente

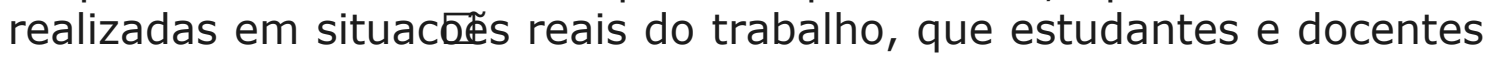


constroem e desenvolvem competências. Orientar o processo ensinoapren-dizagem por competehicia tem, por definică, um carater pratico e social. Os conteud́os passam a ser explorados a partir de problemas específicos, considerando-se o significado a eles atribuido e sua consistencia e funcionalidade para o enfrentamento de situacБॄ̈s reais e complexas. Competência adquire assim uma conotação exclusiva-mente positiva. No entanto, como veremos a seguir, trata-se de um conceito vago, sem uma definição precisa que ao mesclar diferentes conceitos e alvos naõ contribuem para a orientac馬 do desen-volvimento educativo.

\section{A formação por competencias: práctica e performatividade}

O termo competen̋ia, do latim competentia, "proporç ão", "justa relaç ão", significa aptidaõ, idoneidade, faculdade que a pessoa tem para apreciar ou resolver um assunto ou um problema. Na maioria dos dicionários de língua portuguesa, o termo aparece designando a legitimidade e a autoridade de determinadas instituicБّ̋s (por exemplo, o tribunal) para tratar de determinados problemas ou determinadas pessoas (por exemplo, um juíz) para julgar certos pleitos. O termo também aparece como a aptidão que um indivíduo tem de opinar sobre um assunto sobre o qual é versado.

O termo porém é confuso. Ora aparece relacionado à legitimação conferida a um indivíduo de atuar em benefício próprio ou de alguém, ora ao conjunto de conhecimentos necessários para a solução de um problema, ora como capacidade, ora como habilidade, ora como conhecimentos, ora como saber-aplicar algum tipo de conhecimento (v. dicionários Michaelis, Aurélio, entre outros). Como defende a

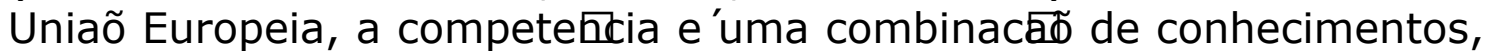
capacidades e atitudes adequadas ao contexto (Estella \& Vera, 2008).

O emaranhado de perspectivas do termo competência espelha a confusão conceitual do mesmo que mais confunde do que esclarece. Ora o termo competência é visto como atribuição, ora como qualificação, ora como uma característica pessoal, ora como um comportamento, ora como uma ação solucionadora de problemas. 0 termo competência, na perspectiva de atribuições e qualificações, é empregado chamando atenção para características extra-pessoais: métodos, boas-práticas, instrumentos. Concomitantemente, o termo, na perspectiva de ações, práticas e comportamentos, chama a atenção para características pessoais ou intra-pessoais.

Nessas várias perspectivas, podemos encontrar diferentes dimensoẽs do termo competentia: saber-saber, saber-aprender, saber-fazer, saber-ser. Definir competencia atraveś de cada uma 
destas dimensoẽs pode ser, no entanto, um esforço em vão e uma empreitada perigosa, uma vez que os saberes fazem parte da competeð̋ia, mas naõ podem ser substituídos, nem se confundem com ela. As competęicias saõ descritas como acб̄̄s e práticas, mas naõ $e^{\prime} o$ fato de descrever as acб̈̈s ou conhecer determinado

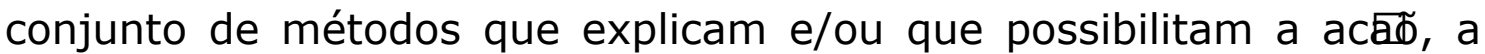
sua performatividade e o seu exito. As competęcias estaõ diretamente relacionadas com o contexto, com um problema e o saber-ser naõ está implićito nesse contexto.

Comparar competência a recursos ou a capital humano, como muitas agências propagam, a uma adição de métodos performativos de saber-saber, saber-fazer, é negligenciar a perspectiva de construção pessoal do ser consigo mesmo e com o mundo. Uma pessoa que é competente não é necessariamente sábia. Assim sendo, competência, mesmo que definida como uma combinatória de elementos em que cada um se modifica em função das características daqueles aos quais se junta levanta sérios problemas conceituais, 0 que torna o conceito, no mínimo, vago e nebuloso.

Será que a meta principal da escola de hoje e' desenvolver competencias que permitam ao sujeito alcancar simplesmente 0 sucesso pessoal e profissional? O objetivo da educação é permitir que cada um aprenda a utilizar os seus saberes para atuar com eficiencia? Que educação é essa que em vez de fomentar o processo de emancipação do ser humano, fomenta em vez disso o caraćter adaptativo do ensino e da aprendizagem? Que escola é essa que valoriza o método em detrimento do conteúdo? Que aprendizagem é essa que prima pela eficácia dos resultados quantificáveis, em prejuízo da transmissaõ de conhecimento, elegendo uma rápida absorvência de conteúdos?

A abordagem por competencias tem como aspecto central o foco nos resultados e menos no processo de aprendizagem. Trata-se de privilegiar o estabelecimento de criteríos e metas que permitam alcancar o objetivo de tornar os estudantes capazes para executar determinadas tarefas ao fim de seu periódo de estudos, bem como instrumentaliza-los para a aprendizagem ao longo da vida. Não é por acaso que instituições financeiras e comerciais estão ávidas a fomentar o desenvolvimento de métodos eficazes de aprendizagem eficiente para solucionar problemas. Saber aplicar um método não significa que estudantes aprenderam alguma coisa. A tendência atual na formação por competências deixa de lado a concepção de educação emancipadora e transformadora para aproximar-se mais do trei- 


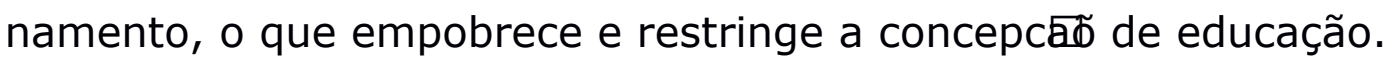

O conceito de competência fundamenta-se numa visão tecnicista e behaviorista do ser humano. A equação utilitarista de métodos didáticos funcionais em salas de aula para atingir metas, subjacente ao conceito de competência, não contribui nem para a formacă

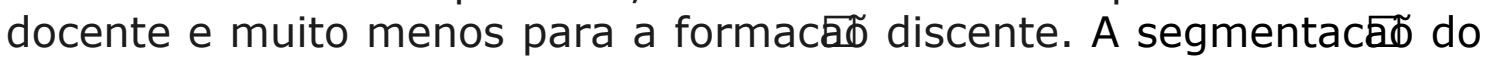
conhecimento, em módulos e especialidades, evoca uma das mais importantes e graves rupturas de nosso tempo. Trata-se do surgimento e implantaca历 da racionalidade tećnica, baseada na produtividade e na competicad. Os criteŕios adotados para a selecad de conhecimentos e habilidades que devem ser aprendidos pelos alunos passa a ser o da utilidade e o de adaptação a um modelo hegemônico alheio à emancipação do ser, algo tão caro e precioso para a educação.

O modelo de competência inerente ao processo de Bolonha reflete essa percepção tecnicista do que venha a ser a relação ensinoaprendizagem (Krautz, 2013). Como afirma Frost (2016) em seu "Parecer acadêmico para o parlamento do Estado sobre a reforma de ensino", apresentado no dia 11.02 .2016 (p. 3), o conceito de competência, que embasa a Reforma de Bolonha, baseia-se numa funcionalidade tecnológica e contraria teorias e reflexões básicas pedagógicas.

"A aprendizagem de um agir competente é compreendida de forma utilitarista como saber-usar e saber-aplicar, sem conhecer exatamente, e sem avaliar sistematicamente, os problemas causados por essa prática (princípio do usuário). A educação, ao contrário, deve expor justamente o que é excluído da caixa-preta do conceito de competência: saber agir e discutir objetiva-mente numa relação interpessoal com conhecimento e responsabilidade." (FROST, 2016, p. 2, tradução HRL).

Aliado ao conceito de competência, a performatividade tem sido considerada criteŕío legitimador da educacă e o desempenho passou a ser medido pela eficiencia dos resultados quantificáveis. Sob a perspectiva performatíca, o conhecimento passa a ser considerado apenas um instrumento de acesso ao mercado de trabalho e seu valor, diretamente proporcional - e temporal - a utilidade que venha a ter para os objetivos economicos momentâneos. A partir dessa lógica, a realidade aparece padronizada a seguir leis próprias (exclusas das relações sociais und interpessoais) de desenvolvimento.

\section{Coclusão}

O modelo de Bolonha, através da modularização dos cursos de 
magistério e ênfase tecnicista em competências e performatividades práticas substitui a responsabilidade pedagógica do futuro docente por uma tecnologia pedagógica que instrui alunos em vez de Ihes despertar o interesse pelo conhecimento. O tempo de formação destinado aos estágios e à prática em salas-de-aula expressam a centralidade do desenvolvimento de "competências" para o ensino no âmbito da socialização profissional dos estudantes. Os métodos padronizados reorganizam as tensões entre conhecimentos científicos específicos e os conhecimentos pedagógicos, os conteúdos que integram esses conjuntos, seus lugares e fontes autorizadas, bem como as interações entre as instituições formativas. O foco da profissionalização e da formação universitária centra-se pois na adaptação do princípio de racionalidade adotada no contexto internacional, fruto dos processos de transferência ou imposição de modelos educacionais tecnicistas e padronizados.

A nossa experiência mostra que o semestre prático não possibilita ao aluno um olhar reflexivo (Bourdieu e Wacquand 1996) à sua prática profissional: teorias e convicções, postura profissional, conhecimentos específicos e conhecimentos didáticos, objetivos e papel docentes, vivências e experiências em aulas.

O e-portfólio auxilia e apoia o estudante nas suas ações pedagógicas, na utilização de métodos desenvolvidos para atingir certos alvos quantificáveis, os quais envolvem um grande número de atores sociais e empresas empenhadas em disceminar as denominadas "best-practice". Ele é um instrumento individual sistemático, onde os progressos práticos profissionais, o desempenho da ação docente e o desenvolvimento de suas competências pedagógicas são document-ados. Há uma coordenação entre os diferentes componentes de ensino e formação de professores, em especial, entre a formação inicial dos professores e a sua formação contínua. Porém, cabe questionar: até que ponto, a formação por competências inclui o reconhecimento de tensões, conflitos e problemas cotidianos inerentes à profissão docente? Será que uma formação por competências auxilia o esclarecimento de importantes questões profissionais situativas na prática de sala-de-aula?

A proṕria cię̋cia da educação e as tecnologias que the saõ correlatas tornam-se um novo mito, uma nova metafiśica que aparentemente naõ pode ser questionada e sim, adaptada. Por sua aura de promotoras do conhecimento seguro, utíl e quantificável, a ciencia e a tecnologia autolegitimam-se, e é justamente essa premissa adaptativa que naõ permite que as regras de seu discurso 
possam ser tematizadas, questionadas, muito menos criticadas.

Ao anuirmos as̀ ideías de que uma boa educacăd e '1) baseada em competências; 2) regida pela padronização de seus métodos e técnicas didáticos; 3) quantificável nos seus resultados; 4) determinada por objetivos que taõ somente preparam os alunos para a realidade pratíca, estamos abdicando de todas as perspectivas emancipatoŕias que podem estar contidas na educação.

\section{Referencias bibliográficas}

Bourdieu, Pierre (1974). Der Habitus als Vermittlung zwischen Struktur und Praxis. In: Bourdieu, Pierre. Zur Soziologie der symbolischen Formen. Frankfurt/M., p. 125-158.

Bourdieu, Pierre e Wacquand, Loïc J. D. (1996). Reflexive Antropologie. Frankfurt/M.

Combe, Arno e Kolbe, Fritz-Ulrich (2008). Lehrerprofissionalität: Wissen, Können, Handeln. In: Werner Helsper. Handbuch der Schulforschung. Wiesbaden: VS Verlag fuĐSozialwissenschaften, p. 857-875.

DECLARACAO DE BOLONHA. Disponível em: http://www.uc.pt/ge3s/ pasta_docs/decl_bolonha/. Acesso em: 15.01.2017.

Estella, A. M., \& Vera, C. S. (2008). La ensenañza en competencias en el marco de la educacioń a lo largo de la vida y la sociedad del conocimiento. Revista IberoAmericana de Educación, 47, 159-183.

Faulstich, Peter e Faulstich-Wieland, Hannelore [Eds.] (2008). Erziehungswissenschaft. Ein Grundkurs. Reinbek bei Hamburg: Rowohlt.

Frost, Ursula. Stellungnahme zum Gesetzentwurf der Landesregierung für ein "Gesetz zur Änderung des Lehrerausbildungsgesetzes" (Parecer acadêmico para o Parlamento Estadual NRW, Alemanha). Drucksache 16/9887. Köln, 11.02.2016.

Humboldt, W. v. (1960): Werke in fünf Bänder, hrsg. von Flitner, A; Giel, K. Darmstadt: Wissenschafltiche Buchgesellschaft.

Hörster, Reinhard. (2010). Bildung. In: Heinz-Herrmann Kruger e Werner Helsper. Einfü hrung in die Grundbegriffe und Grundfragen der Erziehungswissenschaft. Opladen \& Farmington Hills, p.46

Keck, R. W. (1997): Schulbildung im Lichte des europäischen Scholastizismus: eine Geschichte der Instrumentalisierung oder Vervollkommnung? In: Lüth, C. \& Wulf, C. (Hrsg.): Vervollkommnung durch Arbeit und Bildung? Weinheim: Beltz, S. 183-192.

Koller, H.C. (2012). Bildung anders denken. Einführung in die Theorie 
transformatorischer Bildungsprozesse. Stuttgart: Kohlhammer.

Koller, H.C. (2016). Bildung. In: Mecheril, P. Handbuch der Migrationspädagogik. Weinheim: Beltz, p. 32-44.

Krautz, Jochen (2013). Bildungsreform und Propaganda. In: U. Frost \& Rieger-Ladich. Demokratie setzt aus. Gegen die sanfte Liquidation einer politischen Lebensform. Sonderheft der Vierteljahresschrift für wissenschaftliche Pädagogik. Paderborn, p. 86-128.

Westfalen im Bachelor-/Masterstudiengang. Köln (Universität). URL: http://www.unikoeln.de/hf/kostrukt/reich_works/aufsatze/index.html

Roters, Bianca (2012). Professionalisierung durch Reflexion in der Lehrerbildung. Eine empirische Studie an einer deutschen und einer US-amerikanischen Universität. Mußster: Waxmann.

\subsection{Leis e decretos de diretrizes de base da educação alemã:}

Lei de Diretrizes de Base do estado da Renânia do Norte Vestfália (Neuordnung des nordrheinwestfälischen Lehrerausbildungsgesetzes, LABG). 2009. Ministerium fuESchule und Weiterbildung des Landes Nordrhein-Westfalen. Disponível em: www.schulministerium.nrw.de/ BP/Schulrecht/Lehrerausbildung/LABGNeu.pdf.

Decreto para o acesso à docência (Lehramtzugangsverordnung LZV). 2009. [Ministerium fuESchule und Weiterbildung des Landes Nordrhein-Westfalen]. Disponível em: www.schulministerium.nrw.de/ BP/Schulrecht/Lehrerausbildung/LABGNeu.pdf. 